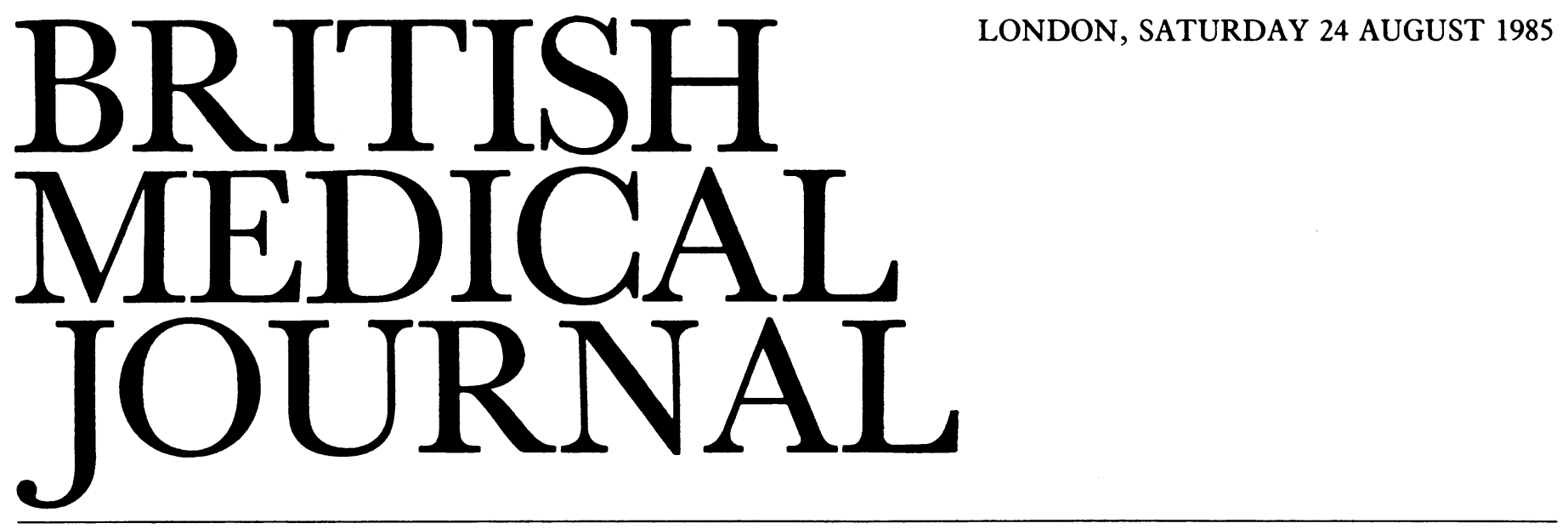

\title{
Treatment of tuberculosis
}

The discovery of rifampicin and ethambutol and the reappraisal of pyrazinamide have led to a new era in the drug treatment of tuberculosis in developed countries. Trials of short term chemotherapy for pulmonary tuberculosis have been reported in the past 10 years.

In 1976 the British Thoracic and Tuberculosis Association recommended a nine month regimen of rifampicin and isoniazid, with ethambutol for two months in the initial phase. ${ }^{1}$ Two surveys have reported on the subsequent use of the 1976 British Thoracic and Tuberculosis Association regimen. The study from south and west Wales covered the years 1976-8; during this period the proportion of patients treated as recommended rose from $16 \%$ to only $22 \%{ }^{2}$ In the more recent Medical Research Council survey of the treatment of pulmonary tuberculosis in England and Wales in $1978-9,53 \%$ of patients were treated as recommended. ${ }^{3}$ The mean duration of chemotherapy of patients completing the 1976 regimen as planned was 11 months, $22 \%$ being treated for more than 12 months. ${ }^{3}$ Both surveys detected the use of several untested drug combinations.

The 1976 regimen is not suitable for all new patients with pulmonary tuberculosis-sensitivity reactions, alcoholism, jaundice, drug resistance, and default may alter the choice of drugs and the duration of treatment. It is unlikely, however, that nearly half of the patients in 1978-9 would have had a clinical reason for requiring a regimen differing from that recommended by the British Thoracic and Tuberculosis Association.

Are there, then, other reasons for the apparent reluctance of respiratory physicians to adopt the newer, short course regimens? The criticisms of the 1976 recommendations $s^{4-6}$ have been answered ${ }^{7-9}$ and centre on the definitions of cure and relapse of the disease. The difficulty of changing doctors' prescribing habits in tuberculosis has been discussed,,$^{10}$ and in part the explanation for the figures from the surveys may lie in the freedom of clinical prescribing in Britain.

Does it matter if treatment is prolonged beyond nine months in compliant patients who have made a good clinical response? Short course regimens should improve compliance by making the course of treatment more acceptable with fewer outpatient attendances and the likelihood of discharge on completion of the course. Prolonging treatment exposes the patient to increased risks of drug toxicity and drug interactions that are difficult to justify. If a patient is unreliable or non-compliant then a fully supervised intermittent regimen would be superior to extending an unsupervised regimen that is not achieving its purpose."
The findings of the two surveys have led to criticism of the view that respiratory physicians should be consulted routinely about proposed courses of antituberculous drugs in nonpulmonary disease $\mathrm{e}^{12}$ and preferably should supervise the drug treatment. ${ }^{13}$ Though there are specialists in other branches of medicine who are particularly interested in the drug treatment of tuberculosis, ${ }^{14}$ is non-pulmonary tuberculosis is rare, ${ }^{16}$ and the occasional prescriber is more likely to make mistakes. ${ }^{17}$ Unfortunately, some textbooks contain errors, and these are the sources that a urologist or gynaecologist might consult. A urological text suggests the addition of streptomycin or pyrazinamide or both, or one of the other drugs, to an initial three drug regimen of isoniazid, rifampicin, and ethambutol in which sensitivity tests have shown resistance to two drugs. ${ }^{18}$ On theoretical grounds resistance might develop to the third drug during the first two months, and thus the addition of only one further drug could be effectively treating with one drug. Fortunately, primary resistance to ethambutol and rifampicin is rare in Britain. A 1981 obstetric text recommends a two drug regimen for the treatment of respiratory tuberculosis in pregnancy. ${ }^{19}$ A 1983 gynaecological text recommends $100 \mathrm{mg}$ isoniazid three times daily with $300 \mathrm{mg}$ rifampicin daily, combined with pyrazinamide in three divided doses daily for pelvic tuberculosis; the dose of rifampicin is inadequate, and isoniazid and pyrazinamide or ethambutol should be given only once daily. ${ }^{20}$ Other texts, however, do recommend that the selection of drugs should be discussed with respiratory physicians in Britain. ${ }^{21} 22$

We still do not know whether the short course regimens achieve as good a result as the 18-24 month regimens of para-aminosalicylic acid (PAS), isoniazid, and streptomycin in extrapulmonary tuberculosis, though the evidence from patients with urological disorders suggests that they may. ${ }^{1523}$

The results of trials in spinal tuberculosis are awaited. Meanwhile, the new drug regimens should be used for nonpulmonary tuberculosis with the continuation phase of two drugs, normally isoniazid and rifampicin, continued for at least 12 to 18 months. There is, however, no reason to continue treatment routinely for pulmonary tuberculosis longer than recommended in the 1976 (or the more recent $1984^{24}$ ) regimen.

Nigel J COOKE

Consultant Physician

General Infirmary,

Leeds LSI 3EX 
1 British Thoracic and Tuberculosis Association. Short course chemotherapy in pulmonary uberculosis. Lancet 1976; ii: 1102-4.

Monie RDM, Hunter AM, Rocchiccioli K, White J, Campbell IA, Kilpatrick GS. Survey of pulmonary tuberculosis in south and west Wales (1976-8). Br Med f 1982;284:571-3.

Medical Research Council Tuberculosis and Chest Diseases Unit. Treatment of pulmonary tuberculosis in patients notified in England and Wales in 1978-9: chemotherapy and hospital admission. Thorax 1985;40:113-20.

4 Buechner HA. Short course chemotherapy for tuberculosis. Ann Intern Med 1981;94:277-8.

5 Buechner HA. Short course chemotherapy for tuberculosis-a story of flawed studies. Am Rev Respir Dis 1981;245:655

6 Buechner HA. When is pulmonary tuberculosis cured? Lancet 1982; i: 1462

7 Anonymous. When is pulmonary tuberculosis cured? [Editorial]. Lancet 1982;i:1163-4.

8 Citron KM, Angel JH, Somner AR. Short course chemotherapy for tuberculosis: a story of flawed studies. Am Rev Respir Dis 1981;124:658.

9 Darbyshire J, Fox W, Girling DJ, Nunn AJ, Mitchinson DA. Short course chemotherapy for tuberculosis: a story of flawed studies. Am Rev Respir Dis 1981;124:658-60.

10 Fox W. Compliance of patients and physicians: experience and lessons from tuberculosis - II. $B$ Med J 1983;287:101-

1 British Medical Research Council. Co-operative controlled trials of a standard regimen of streptomycin, PAS and isoniazid and three alternative regimens of chemotherapy in Britain. Tubercle 1973;54:99-129.

12 Gow JG. Management of extra-pulmonary tuberculosis. Br Med f 1982;285:894-5.

13 Crofton JW. Treatment of tuberculosis. Br Med $\mathcal{F}$ 1979;i:52.

14 Parsons M. Tuberculous meningitis-a handbook for clinicians. Oxford: Oxford University Press, 1979

15 Gow JG, Barbos AS. Genitourinary tuberculosis. A study of 1117 cases over a period of 34 years. Br f Urol 1984;56:449-55.

16 Byram D, Hatton P, Williams SE, Pearson SB. The form and presentation of tuberculosis over a 10 year interval in Leeds. Br $\mathcal{f}$ Dis Chest 1985;79:152-60

17 Wardman AG, Williams SE, Curzon PGD, Page RL, Cooke NJ. Tuberculosis: who should prescribe? BrMed f 1982;284:569-71.

18 Laidlaw M. Renal tuberculosis. In: Chisholm GD, Williams DI, eds. Scientific foundation of Laidlaw M. Renal tuberculosis. In: Chisholm GD, Williams DI, eds. Sciont
urology. 2nd ed. London: William Heinemann Medical Books, 1982:222-7.

9 Malkasian GD. Respiratory diseases and pregnancy. In: Iffy L, Kaminetzky HA, eds. Principles and practice of obstetrics and perinatology. Vol 2. New York: John Wiley and Sons, 1981:1311-4. 20 Barnes J. Female genital tuberculosis. In: Lecture notes on gynaecology. Sth ed. Oxford: Blackwell Scientific Publications, 1983:67-70

21 Griffiths DLL. The treatment of spinal tuberculosis. In: McKibbin B, ed. Recent advances in orthopaedics. Vol 3. Edinburgh: Churchill Livingstone, 1979:1-17.

22 Sutherland AM. Gynaecological tuberculosis. Br f Hosp Med 1979;22:569-76.

23 Wong SH, Lau WY, Ho KK, Fan ST, Yiu TF, Chan SL. The management of urinary tuberculosis-a logical approach. Br $\mathcal{J}$ Urol 1984;56:349-53.

24 British Thoracic Society. A controlled trial of 6 months' chemotherapy in pulmonary tuberculosis. Final report: results during the 36 months after the end of chemotherapy and beyond. $\mathrm{Br} \mathcal{F} \mathrm{Dis}$ Chest 1984:78:330-6.

\section{Surgery and the pill}

After major surgery the relative risk of overt, clinical, deep venous thrombosis in women taking oestrogen containing combined oral contraceptives is about two, as compared with non-users. ${ }^{12}$ This estimate is approximate for many reasons: the risk appeared higher in early studies, ${ }^{3}$ whereas the increasing use of formulations containing less than $50 \mu \mathrm{g}$ oestrogen implies that the real risk of all forms of venous thromboembolism may have come down. ${ }^{4}$

Metabolic studies show numerous changes in factors associated with blood coagulation and fibrinolysis, whose overall effect, even with our current pills, would be expected to predispose to deep vein thrombosis. ${ }^{12}$ Anaesthesia and the combined oral contraceptives have additive effects on at least one important factor (both reduce the activity of antithrombin III). ${ }^{5}$ Even if the relative risk with 30-35 $\mu \mathrm{g}$ oestrogen pills is now less than two the attributable risk if women continued to take them during and after major surgery would be high, because venous thromboembolism after major surgery is one of the commonest serious complications of the combined oral contraceptive. ${ }^{12}$ The risk is greatest after major orthopaedic, abdominal, and cancer surgery or any surgery that entails giving a hypotensive anaesthetic.

On p 516 there is another risk to which attention is drawn-namely, unwanted pregnancy when the oral contraceptive pill is discontinued before surgery. This is a risk that needs to be clearly explained to the woman and her partner, and the couple should be helped to organise alternative means of contraception. (Many couples who have become used to the convenience of the combined oral contraceptive for several years have no notion of how easy it is to conceive unless barrier methods are used with obsessional care.) Steps must also be taken to ensure that an early pregnancy is not present before proceeding with elective anaesthesia and surgery.

To reduce this risk of pregnancy further three questions need to be answered: For which procedures is it unnecessary to discontinue the combined pill? Do the restrictions apply to the progestogen only pill, or other oestrogen free preparations? and How long before and after surgery should oral contraceptives be avoided?

The risk of deep venous thrombosis after minor surgery, such as most dental procedures and laparoscopy, with a short duration of anaesthesia and full mobilisation the same day, is vanishingly small. Hence any extra risk associated with the combined oral contraceptive would be more than outweighed by the risk of pregnancy. The only exception would be minor procedures to the legs themselves-notably varicose vein surgery and injection sclerotherapy. Metabolic studies have generally failed to show any important effects of progestogens in promoting intravascular coagulation ${ }^{6}$; thus the progestogen only pill need not be avoided over the time of elective surgery, however major. Indeed, the injectable progestogens such as Depo-Provera might well be offered as perioperative "cover" to women on the waiting list for a major procedure.

Finally, the time of avoidance of the combined oral contraceptive should be reduced to the minimum commensurate with safety. Published epidemiological studies suggest that the excess risk of deep venous thrombosis is unrelated to duration of use and reverts to normal within less than one month. ${ }^{7}$ Some changes in the coagulation and fibrinolytic systems have been detected about six weeks after discontinuing oestrogens, but others-such as the decreased activity of antithrombin III-have reverted to normal within four weeks. ${ }^{8}$ Avoiding combined oral contraceptives for six weeks preoperatively may be the counsel of perfection, but four weeks is probably more realistic. Postoperatively most agree that the combined oral contraceptive may be restarted two weeks after the patient is fully mobile. ${ }^{910}$

Taking all factors into consideration, I believe that the following - which is essentially that which will appear in the forthcoming issue number 10 of the British National Formulary, para 7.3.1-represents good policy: oestrogen containing contraceptives should be discontinued (and adequate alternative contraceptive arrangements made) four weeks before major elective surgery; they should normally be started again at the first menses occurring at least two weeks after the procedure. When discontinuation is not possiblefor example, after trauma or if, by oversight, a patient admitted for an elective procedure is still taking an oestrogen containing oral contraceptive-prophylactic low dose subcutaneous heparin should be considered. ${ }^{5}$ These recommendations do not apply to minor surgery with short duration of anaesthesia and early mobilisation-for example, laparoscopic sterilisation or tooth extraction-or to women taking oestrogen free contraceptives.

It is important to plan ahead: not only must this matter be discussed in the outpatient department but also women must be given at least a month's warning of their admission or (preferably) a definite date from the clinic. Other risk factors must receive due weight, notably obesity and a family history of venous thrombosis. The latter implies that the patient should be investigated preoperatively for any factors that might either promote thrombosis or impair fibrinolysis. It is also helpful to instruct women to restart the combined oral 